\title{
Bending in Laminas of NFPR: Type of Reinforcement, Fracture and Properties
}

\author{
Mirtânia Antunes Leão ${ }^{a}$, Sérgio Renan Lopes Tinô ${ }^{b *}$, \\ Raphael Siqueira Fontes ${ }^{\mathrm{b}}$, Eve Maria Freire de Aquino ${ }^{\mathrm{b}}$ \\ a'Departamento de Tecnologia Mecânica e Materiais, Instituto Federal da Bahia - IFBA, \\ Rua Emídio dos Santos, CEP 40301-015, Barbalho, Salvador, BA, Brazil \\ ${ }^{\mathrm{b}}$ Programa de Pós-Graduação em Engenharia Mecânica, \\ Campus Universitário, Centro de Tecnologia, Universidade Federal do Rio Grande de Norte - UFRN, \\ CEP 59072-970, Lagoa Nova, Natal, RN, Brazil
}

Received: October 27, 2010; Revised: February 8, 2011

\begin{abstract}
Natural fiber reinforced plastics (NFRP) have awakened considerable interest in the area of polymer composites, because of the need to develop new, environmentally friendly materials. One of the most complex ways of manufacturing this type of material is in the form of ultrathin laminar layers; however, this process hinders mechanical testing, mainly three and four-point bending. The present investigation faces this challenge and shows the influence of parameters, such as the grammage of reinforcing fabric and lamination process, on strength, stiffness and fracture characteristics for three-point bending in this type of structural element. The industrially manufactured laminas were composed of orthophthalic polyester resin reinforced with licuri fibers. Macromechanical and micromechanical analyses were conducted in the study of fracture characteristics for all the parameters. The mechanical behavior in the three-point bending of the laminar composite showed that the use of licuri fiber to obtain natural fiber-based plastic is completely viable.
\end{abstract}

Keywords: reinforced plastic, licuri fibers, mechanical properties, fracture

\section{Introduction}

Composite materials, which result from the combination of two or more materials that exhibit better properties than their original structures, have become increasingly important in a host of industrial applications ${ }^{1}$.

The structural application of composite materials has grown in recent decades because of improvements in manufacturing processes involved, as well as designing of new reinforcement fabrics and laminar structures ${ }^{2,3}$.

The use of natural fiber-based polymer composites, also known as natural fiber- reinforced plastics (NFRP), has also increased, mainly in structural elements submitted to small loads. This is because natural fibers generally exhibit worse mechanical properties than those of synthetic fibers, precluding their use in medium and high-performance structural elements ${ }^{4,5}$.

The search for new composites that use natural fibers, or a mixture of natural and synthetic fibers (hybrid composite) as reinforcement, aims at decreasing this impact on the environment, since part of synthetic reinforcement is replaced by natural fibers.

Despite the limited structural application of NFRP, there are many other possible applications, mainly in packaging, automobile accessories, different types of wrapping, among others. Other advantages of natural over synthetic fibers are cost, light weight and strength. However, some of these fibers also pose problems with respect to mechanical performance, moisture absorption, among others. This does not prevent further investigation aimed at improvements in final performance. On the contrary, researchers should seek to develop new materials that meet desired structural expectations ${ }^{6}$.

The purpose of the present study is to investigate mechanical behavior, under a three-point bending load, of natural fiber-reinforced plastic, a new material that uses licuri fibers as natural reinforcement. This type of loading was selected because fiber/matrix interface adherence is extremely important in final material performance, a parameter that stands out in this test, mainly if laminas are used.

Licuri fibers, a promising candidate to meet this challenge, comes from the Syagrus coronata (Martius) Becari palm tree, Figure 1a and b, abundantly found in the state of $\mathrm{Bahia}^{7}$. Some important information about the physical, morphology and mechanical properties of licuri fibers can be found in references ${ }^{6,8}$.

Licuri fiber, obtained from the palm leaf, is sufficiently malleable to be woven. A unidirectional fabric, obtained on a manual loom, was used in this study. It was impregnated with orthophthalic polyester resin, giving rise to laminar composites

In the proposed study, special attention was given to studying the influence of parameters, such as the grammage of reinforcement fabric, on strength, stiffness and fracture characteristics. Two different grammages were used for the licuri fiber: G1 fabric (low grammage) and G2 fabric (high grammage), corresponding to two different laminar composites denominated LG1 (laminar composite with grammage 1) and LG2 (laminar composite with grammage 2).

Finally, a comparative study of the two grammages was conducted, as well as macroscopic and microscopic (optical) analysis of mechanical fracture characteristics.

\section{Materials and Methods}

The composite material created in this study had a laminar structure, that is, only one reinforcing fabric layer was impregnated. Since natural licuri fiber was used as reinforcing material, the fabric was manufactured from this fiber. 
These fibers come from the city of Caldeirão Grande, in the semiarid region of Bahia. They were removed from licuri palm trees growing in the same soil. The unidirectional fabric was produced on a manual loom.

The grammages obtained in the licuri fiber fabrics used in the present study were 418.21 and 572.48 g.m $\mathrm{m}^{-2}$ for grammages $\mathrm{G} 1$ and G2, respectively. Figure 2 shows the unidirectional licuri fiber fabrics. The purpose of the transverse fibers observed in the fabric was to keep the strands parallel.

Laminar composites were obtained industrially (Tecniplast Ind. \& Comércio Ltda.) in the form of sheets (laminas), using the hand lay-up technique, where licuri fiber fabric was impregnated with orthophthalic polyester resin (Novapol L120), very common process in the reinforced plastic industry. The laminar composites were denominated LG1 (grammage 1) and LG2 (grammage 2).

The manufactured sheets were $45 \mathrm{~cm}$ wide and $65 \mathrm{~cm}$ long. The "in natura" fibers were not previously treated to avoid increasing production costs and to study the "real" interface adherence of this type of fiber with polyester resin.

The mechanical behavior of laminar composites was determined by the three-point bending test. This type of test was used because three and four-point bending conducted with laminas can be used as a qualitative assessment of adherence to a fiber/matrix interface. This qualitative assessment is achieved using a comparative study of properties involving different parameters related to the composite manufacturing process.

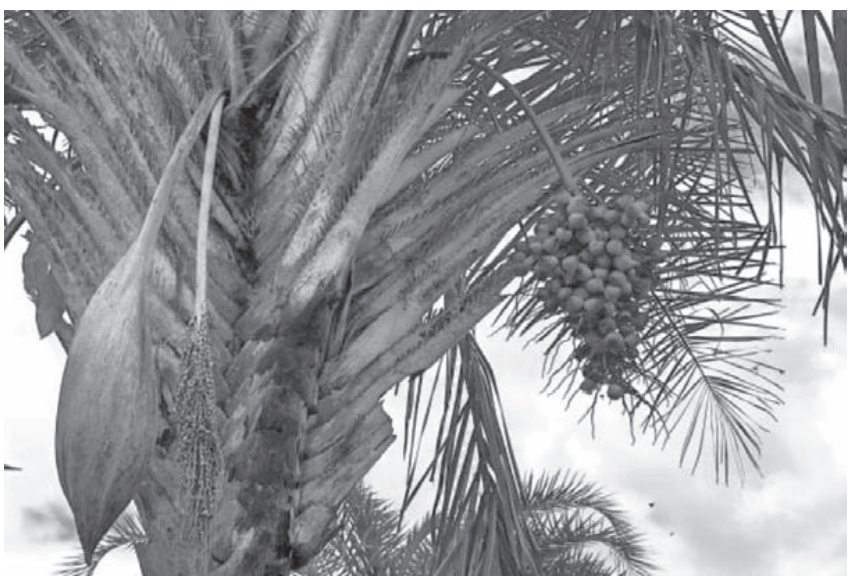

(a)

Figure 1. a) Licuri tree (Syagrus coronata); and b) "in natura" licuri fibers.
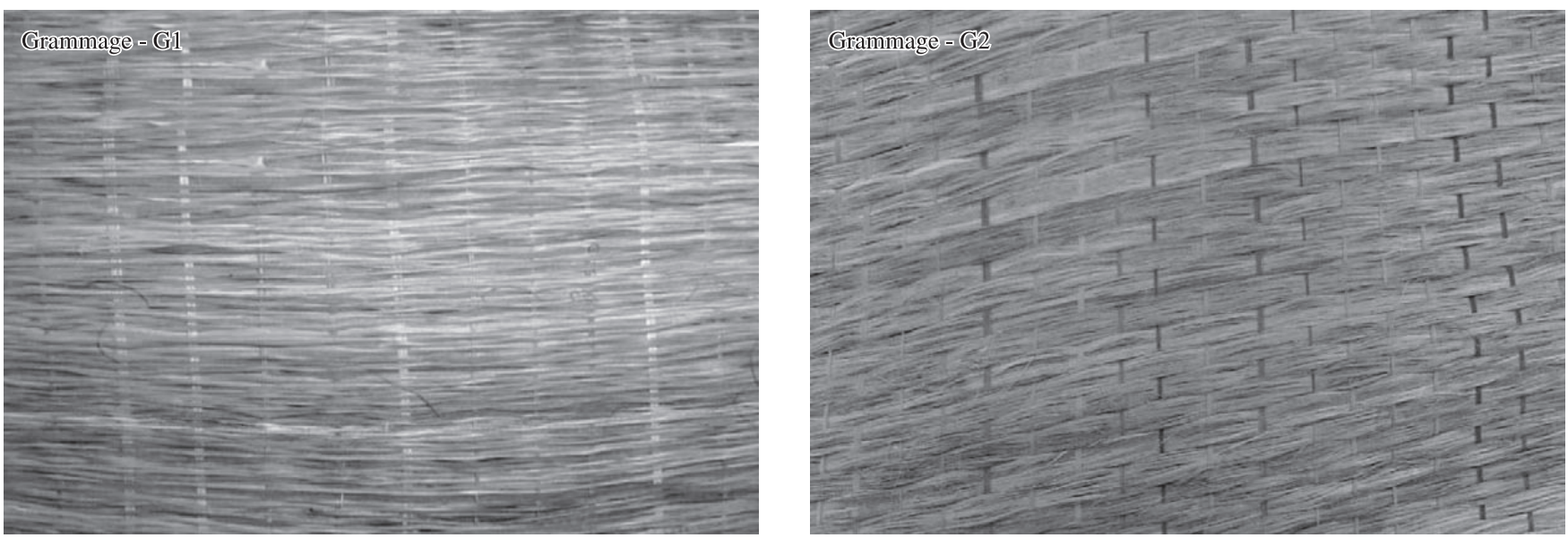

The three-point bending tests were conducted at ambient temperature of $25 \pm 2{ }^{\circ} \mathrm{C}$, on a Shimadzu AG-I universal testing machine. The test specimens were cut with a diamond wire and their sides were smoothed and polished according to metallographic techniques. Mean test specimen sizes and test specifications (Table 1) followed ASTM D790-079. All test specimen dimensions were within required tolerances of $\pm 1 \%$.

Eight test specimens were assayed for each lamina and bending strength was defined as the stress at which failure occurs. It is measured on the bottom surface (where tensile stresses occur) of the test specimen. Stiffness values (elasticity modulus) were determined before damage onset and according to the equation established in the norm.

Previously fractured test specimens were analyzed and microscopic and macroscopic analyses of these specimens were conducted to study the final characteristics of the mechanical fracture. An optical microscope (Olympus MG) was used for microscopic analysis.

\section{Results and Discussion}

\subsection{Three-point bending test for laminar composites}

Three and four-point bending tests for laminar composites (a single lamina) exhibit peculiar characteristics in their mechanical responses, compared to tests conducted in laminate composites. When

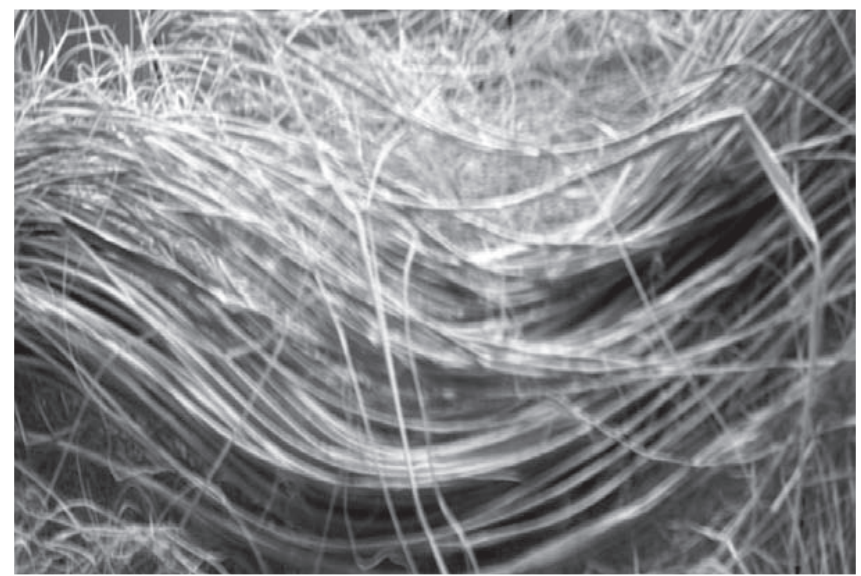

(b)

Figure 2. Unidirectional licuri fiber fabrics. 
the composite is in laminate form (composed of two or more layers), the mechanical bending response, mainly with respect to fracture, is visibly located in the tensile layers, exhibiting the characteristic response of bending tests ${ }^{10}$. This occurs because the structural element is thick enough for the fracture to be restricted to these layers.

In the case of bending tests with laminar composites, especially three-point bending, the mechanical response is unpredictable due to the small thickness. Since only a single reinforcing layer is involved, the manufacturing process used to obtain the composite influences the damage mechanism and in turn, the response of the material to this load.

The hand lay-up manufacturing process used to obtain the composites produced both resin-rich (surface in contact with the mold) and fiber-rich regions (opposite surface), irrespective of grammage type. This means that the bending response of the composite depends on the surface to which the load is applied. In the case in question, the test specimens exhibited both resin-rich and fiber-rich regions along their length, in addition to "undulation" characterized by the deviation of fiber orientation, given that a unidirectional lamina was used (Figure 3).

In the bending test a line load (loading nose) is applied and depending if the central region of the test specimen (load application section) coincides with a resin- or fiber-rich region, the load at damage onset may vary and thus influence strength (ultimate strength) to laminar bending. Therefore, all the tests were conducted considering the load application surface in contact with the mold during the hand lay-up process; that is, the bottom surface where fracture is characterized by bending becomes the region with the greatest likelihood of having a higher percentage of fibers and consequent greater strength to bending in the composite. Figure 4 shows the stress $\times$ deflection diagram obtained on the testing machine, for composite LG1.

Figure 4 shows that each curve inflection corresponds to a fracture (crack) in the resin during the entire test. As the resin fractures, the load is transferred to the fibers, characterizing new load support capacity in the composite. It is also observed that the lower the load

Table 1. Dimensions (mean values) and specifications for the three-point bending test.

\begin{tabular}{ccc}
\hline & Composite LG1 & Composite LG2 \\
\hline Thickness (mm) & 2.5 & 2.8 \\
Width (mm) & 25 & 25 \\
Total length (mm) & 60 & 80 \\
Span (mm) & 40 & 50 \\
Displacement & 1.0 & 1.3 \\
velocity (mm/min) & & \\
Load application site & Center of the span & Center of the span \\
\hline
\end{tabular}

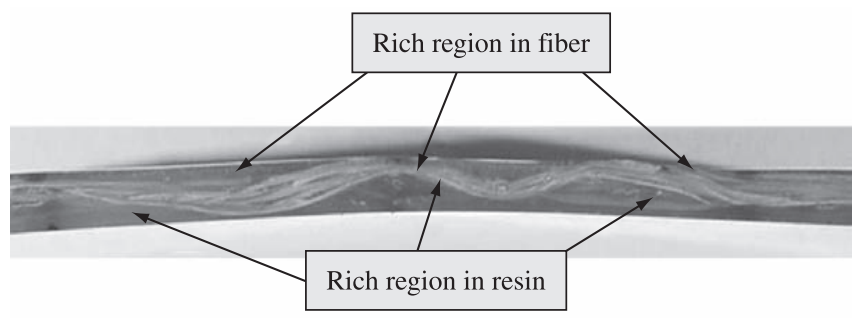

Figure 3. Undulations in fibers originating rich regions in resin and fiber-LG1. intensity at which curve inflection occurs (position of the first crack on the tensile side coincides with a resin-rich resin), the lower the ultimate strength to composite bending. The mechanical properties of this type of structure (lamina) then depend strongly on resin properties.

The mean values obtained in the three-point bending test for ultimate strength, elasticity modulus and fracture deflection, as well as their respective dispersions for composite LG1, are shown in Table 2 . In both composites, the elasticity modulus was calculated for a deflection range before onset damage load and dispersions were calculated as the absolute difference between maximum and minimum values.

The large dispersion found for mechanical properties is due mainly to the influence of the manufacturing process to obtain laminar structures, given that the previously mentioned resin- and fiber-rich regions have a direct influence on both onset damage load and final composite response. These results support the qualitative character of the test, but are only valid in comparative studies.

The results obtained in the three-point bending test for composite LG2 are reproduced in the stress $x$ deflection graph shown in Figure 5. Inflections occur with less intensity, causing inter-curve linearity to become more harmonious; that is, even linearity between stress and deflection can be considered.

Despite the lower dispersion in ultimate strength and elasticity modulus results for LG2, compared to those obtained with LG1, curve inflections at onset of resin damage exhibited similar behavior.

Table 3 gives mean mechanical property values for composite LG2, with respect to ultimate strength, elasticity modulus and fracture deflection, as well as the respective dispersions found in the threepoint bending test.

\subsection{Fracture analysis for laminar composites}

The final loss of support load for composites LG1 and LG2 resulted from complete rupture of the resin in the central region and on the tensile side of the test specimen, but without fiber rupture. In this

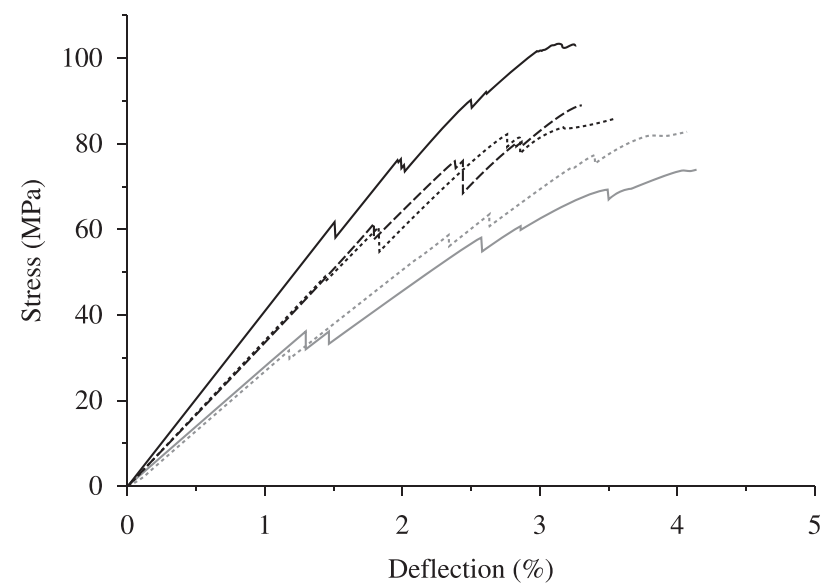

Figure 4. Stress $\times$ deflection diagram for composite LG1 - Three-point bending.

Tabela 2. Propriedades mecânicas para o compósito LG1.

\begin{tabular}{ccc}
\hline Mechanical properties & Mean values & Dispersions $(\%)$ \\
\hline Ultimate stength $(\mathrm{MPa})$ & 85.37 & 27.81 \\
Elasticity Modulus $(\mathrm{GPa})$ & 3.29 & 31.36 \\
Deflection $(\%)$ & 3.66 & 21.13 \\
\hline
\end{tabular}


case, the structural element loses its entire load support area, making deflection excessive, without fiber breakage. Figures $6 a$ and $b$ show final fracture of the test specimen, where resin rupture without fiber breakage is observed, while Figure 7 depicts excessive deflection. Both characteristics were observed in the two laminar composites under study.

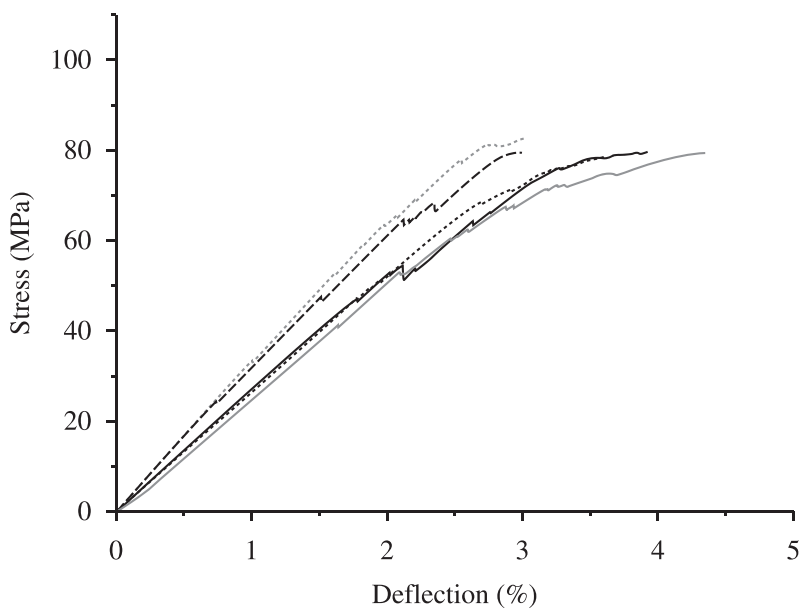

Figure 5. Stress $\times$ deflection diagram for composite LG2 - Three-point bending.

Table 3. Mechanical properties of composite LG2.

\begin{tabular}{lcc}
\hline \multicolumn{1}{c}{ Mechanical properties } & Mean values & Dispersions $(\%)$ \\
\hline Ultimate strength $(\mathrm{MPa})$ & 78.58 & 12.40 \\
Elasticity modulus $(\mathrm{GPa})$ & 2.84 & 21.78 \\
Deflection $(\%)$ & 3.58 & 31.04 \\
\hline
\end{tabular}

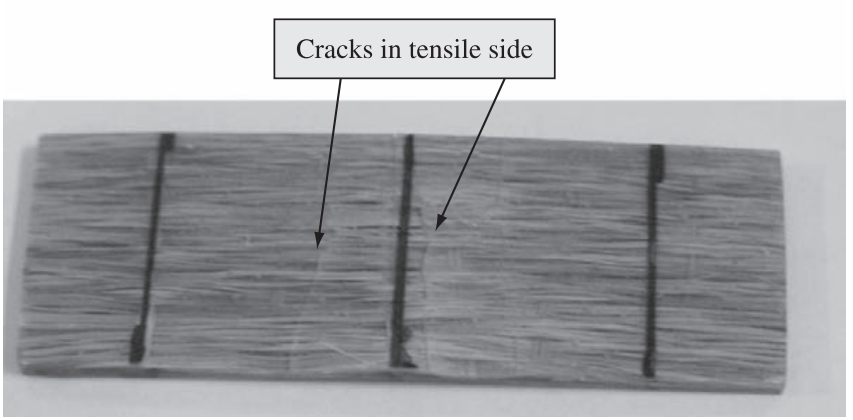

(a)

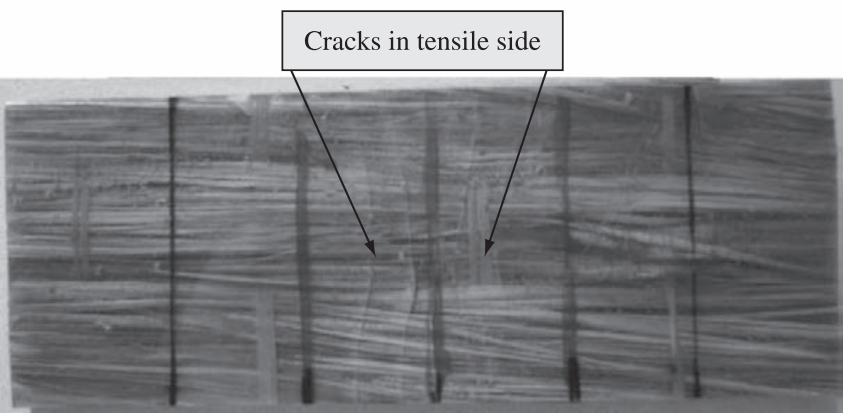

(b)

Figure 6. Test specimen fractured in the three-point bending test: a) composite LG1; and b) composite LG2.
With respect to fracture analysis under optical microscope for composite LG1, Figure 8 shows the occurrence of total resin fracture without licuri fiber breakage. Figure 9 illustrates the presence of transverse cracks in the resin that do not rupture the fiber, but spread to the entire resin region. Micrographs depict the central region of the test specimen and the tensile side.

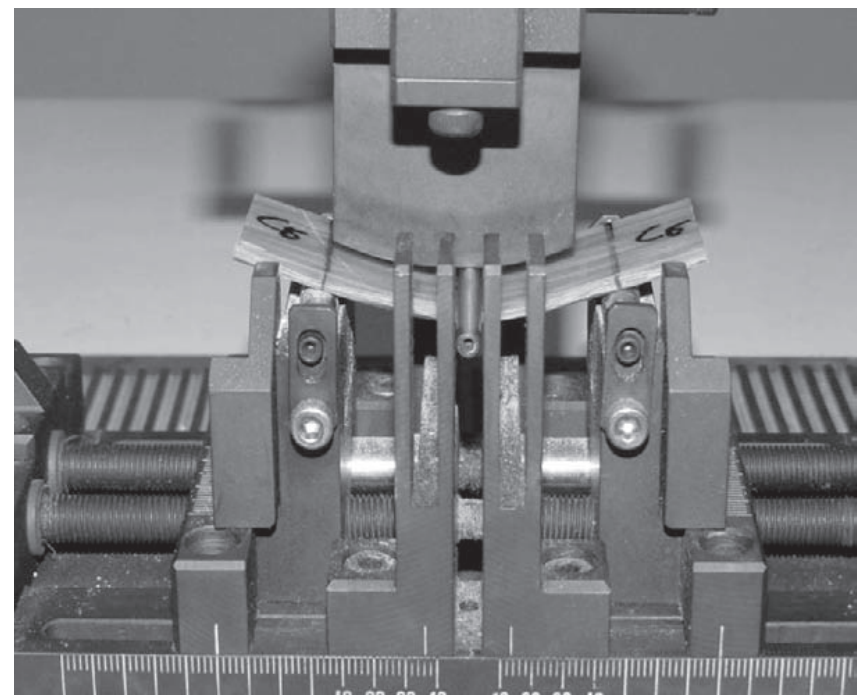

Figure 7. Excessive deflection in the three-point bending test - composite LG2 .

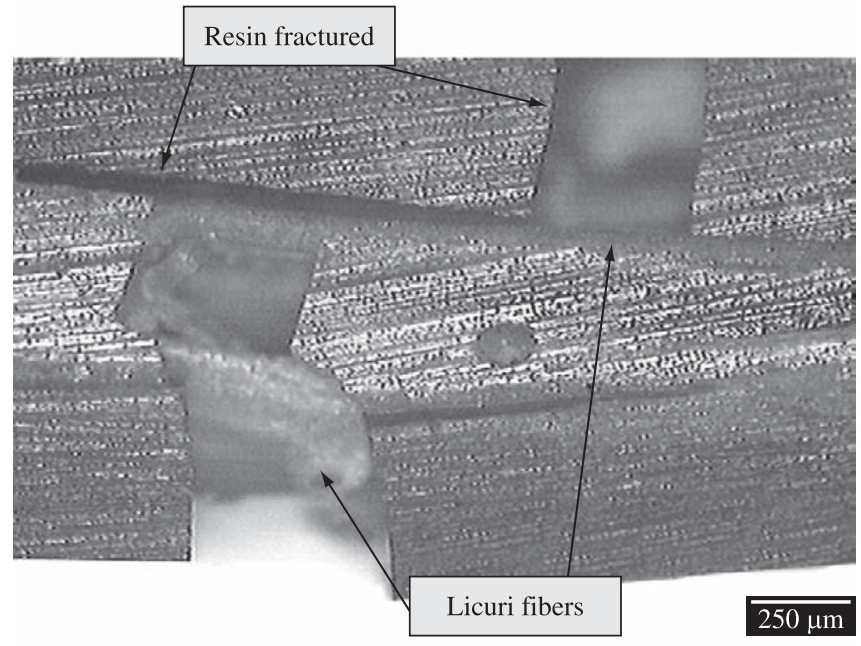

Figure 8. Total resin fracture without licuri fiber breakage in composite LG1.

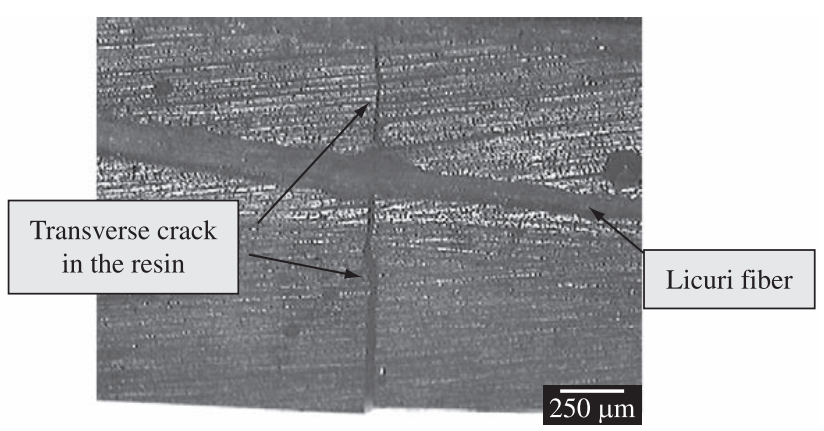

Figure 9. Transverse crack in the resin without licuri fiber damage in composite LG1. 
For composite LG2 optical microscopy showed similar damage characteristics to those observed in composite LG1 (Figure 10), where total resin fracture without affecting licuri fiber occurred.

Also in relation to composite LG2, Figure 11 demonstrates that the fracture occurring in the matrix does not result in fiber breakage, but only slight fiber/matrix detachment, called adhesive fracture. However, this characteristic was not observed for composite LG1.

This type of fracture response is not observed in the natural fiberbased laminated composite. Not only is total rupture observed, but also localized damage, mainly in the region below the neutral line (tensile side), in which other fracture characteristics can be observed ${ }^{11}$.

Comparative study of mechanical properties for composites LG1 and LG2

A comparative study of mechanical properties in three-point bending of composites LG1 and LG2 is shown in Figure 12.

The following percentage differences in mean mechanical properties between composites LG1 and LG2 were observed: ultimate strength: $+7.95 \%$; elasticity modulus: $+13.68 \%$ and deflection: $+2.19 \%$.

Despite the complexity of the test and its bending response, the percentage differences between the composites are within the normal range. There is therefore no marked superiority between them in terms of the influence of grammage.

A marked characteristic that should be underscored is the fact that both composites exhibited very similar deflection, indicating that there is no superiority in bending capacity, even with different fabric grammages in the composites analyzed.

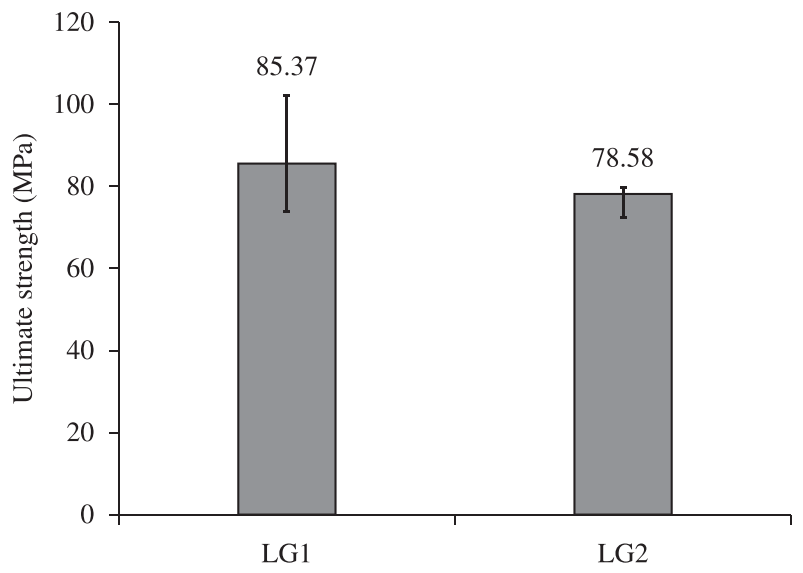

(a)

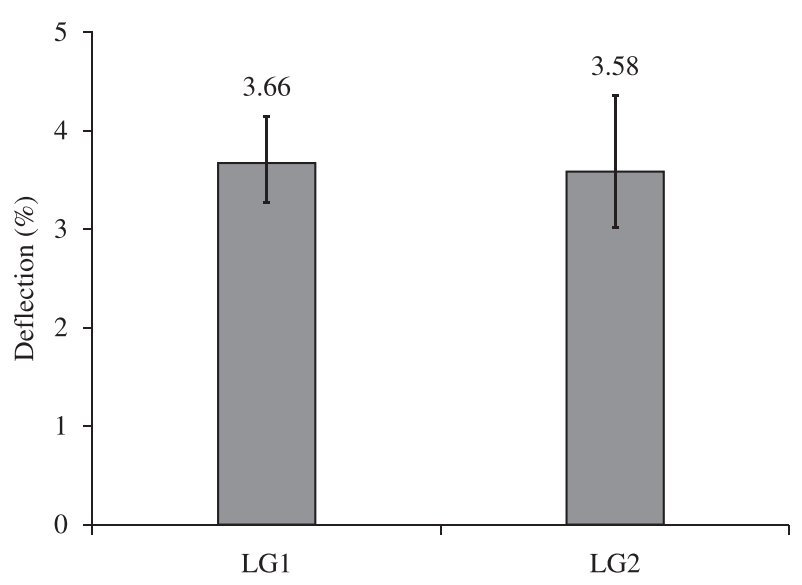

(c)

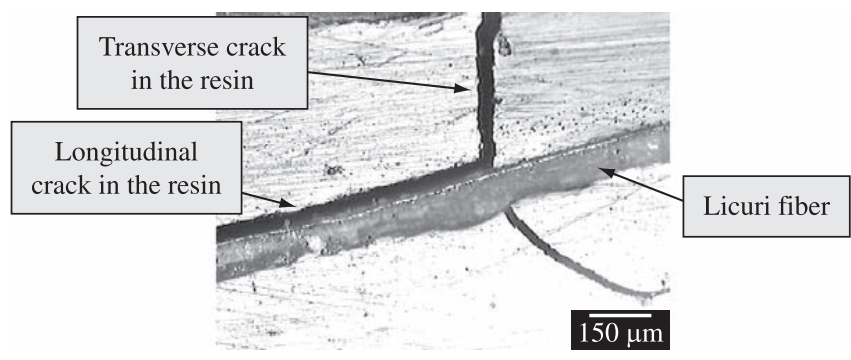

Figure 10. Transverse crack in the resin without licuri fiber damage in composite LG2.

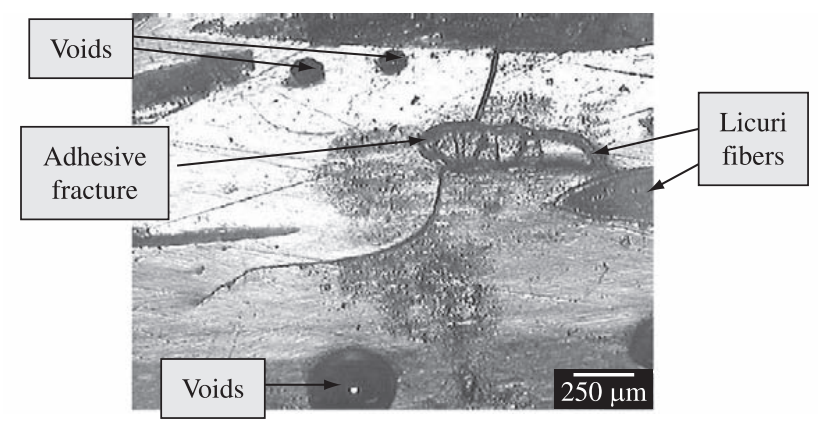

Figure 11. Adhesive fracture in composite LG2.

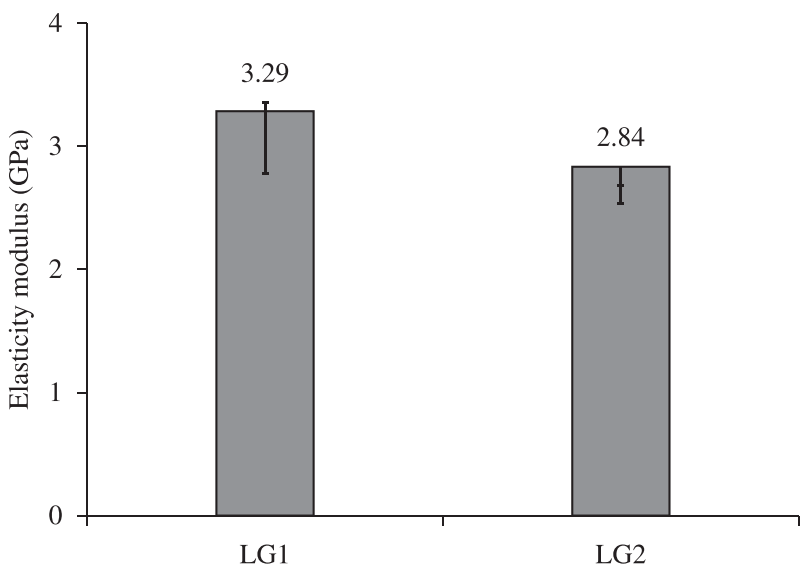

(b) 


\section{Conclusions}

The following conclusions can be drawn from the study results:

- Compared to other natural fiber-based laminar composites ${ }^{4,12}$, composites LG1 and LG2 showed comparable mechanical properties, with respect to three-point bending;

- Overall mechanical behavior of the laminar composite in threepoint bending demonstrates that resin properties predominate, characterizing the non-influence of reinforcement fabric grammage;

- The presence of excessive deflection in both laminates resulted in total resin rupture without licuri fiber breakage;

- The presence of adhesive fracture on the fiber/matrix interface was observed only for composite LG2; and

- The use of licuri fiber is completely viable if compared with other natural fibers like reinforcement to reinforced plastics.

\section{Acknowledgements}

The authors acknowledge the financial support provided by CNPq and CAPES.

\section{References}

1. Herakovich CT. Mechanics of fibrous composites. New York: Ed. Wiley; 1997. $460 \mathrm{p}$.

2. Yijun J and Suong VH. A novel method for the manufacturing of thick composites. Journal of Composite Materials. 2006; 40(5):433-453.

3. Susan CM and George SS. Manufacturing process models for thermoplastic composites. Journal of Composite Materials. 1992; 26(16):2348-2377.
4. Aquino EMF, Sarmento LPS, Oliveira W and Silva RV. Moisture effect on degradation of jute/glass hybrid composites. Journal of Reinforced Plastics and Composites. 2007; 26(2):219-233.

5. Moe MT and Liao K. Effect of environmental aging on the mechanical properties of bamboo-glass fibre reinforced polymer matrix hybrid composites. Composites Part A. 2002; 33:43-52.

6. Leão MA, Aquino EMF, Fontes RS and Tinô SRL. Alternative Fiber to Reinforced Plastics. In: Proceedings of 20th International Congress of Mechanical Engineering - COBEM; 2009, Gramado, Nov. 15-20. p. 1-10.

7. Noblick LR. The indigenous palms of the State of Bahia. Brazil. [PhD Thesis]. Chicago: University of Illinois; 1991.

8. Leão MA, Duarte FJB and Aquino EMF. Caracterizações química, física, mecânica e microestrutural das fibras de licurí. In: IX Congreso Iberoamericano de Ingeniería Mecánica-CIBIM; 2009, Las Palmas de Gran Canaria. Nov. 15-20. p. 12/68-12/75.

9. ASTM D 790-07, 2007. Standard test method for flexural properties of unreinforced and reinforced plastics and electrical insulating materials. In: Annual Book of ASTM Standards. West Conshohocken, Pennsylvania, USA.

10. Yang B, Kosey V, Adanur S and Kumar S. Bending, compression and shear behavior of woven glass fiber-epoxy composites. composites - Part B. Engineering. 2000; 31:715-721.

11. Silva RV, Aquino EMF, Rodrigues LPS and Barros ARF. Curaua/glass hybrid composite: the effect of water aging on the mechanical properties. Journal of Reinforced Plastics and Composites. 2009; 28(15):1857-1868.

12. Munikenche Gowda T, Naidu ACB and Rajput Chhaya. Some mechanical properties of untreated jute fabric-reinforced polyester composites. Composites: Part A. 1999; 30:277-284. 